\title{
Isolation and identification of Candida tropicalis in sows with fatal infection: a case report
}

Lufeng Zhai, Ying Zhou, Yingxia Wu, Yunyun Jin, Qiaoyan Zhu, Shengguo Gao, Xuefeng Li, Zhe Sun, Yan Xiao, Baicheng Huang ${ }^{*}$ and Kegong Tian ${ }^{*}$

\begin{abstract}
Background: Candida is the common conditionally pathogenic fungus that infected human and animal clinically. C. tropicalis had been isolated from the skin and hair of healthy pigs, but with no report of fatal infection in gastrointestinal diseases.

Case presentation: In a pig farm in Henan Province of China, about $20 \%$ of pregnant and postpartum sows suffered from severe gastrointestinal diseases, with a mortality rate higher than $60 \%$ in the diseased animals. The sows had gastrointestinal symptoms such as blood in stool and vomiting. Necropsy revealed obvious gastric ulcers, gastrointestinal perforation, and intestinal hemorrhage in the gastrointestinal tract, but no lesions in other organs. The microbial species in gastric samples collected from gastric ulcer of the diseased sows then was initially identified as Candida by using routine systems of microscopic examination, culture characteristics on the medium Sabouraud dextrose agar medium. The fungus was further identified as C. tropicalis by species-specific PCR and sequencing. This study revealed an infection of $C$. tropicalis in sows through gastrointestinal mucosa could cause fatal digestive system disease and septicemia.

Conclusions: For the first time, a strain of C. tropicalis was isolated and identified from the gastric tissue of sows with severe gastrointestinal diseases. PCR and sequencing of ITS-rDNA combined with morphology and histopathological assay were reliable for the identification of Candida clinically.
\end{abstract}

\section{Background}

Candida is the common conditionally pathogenic fungus that infected human and animal clinically by the species of Candida albicans, Candida tropicalis, Candida glabrata, Candida parapsilosis, and Candida krusei [1]. Candida can invade the skin, mucosa, and the internal organs, with two common syndromes of mucocutaneous candidiasis and invasive or deep organ candidiasis [2].

C. tropicalis is widespread in the environment, human skin, vagina, mouth, digestive tract, which would become pathogenic rapidly after alteration of the host immune

* Correspondence: hbch228@163.com; vetvac@126.com National Research Center for Veterinary Medicine, No.3 Cuiwei Road, High-Tech District, 471003 Luoyang, Henan, PR China system, causing the localized and even systemic infection $[3,4]$. It was reported that in addition to human beings, C. tropicalis had been isolated from the skin and hair of healthy pigs, the feces of healthy poultry, the nasal cavity of healthy horses, the urine of dogs with cystitis and the external auditory canal of dogs and cats with otitis externa [5-8]. The infection of C. albicans is the main cause of gastrointestinal candidiasis in pigs. To date, there have been no report of lethal infection by C. tropicalis in pigs through digestive tract. In this study, the infection of C. tropicalis was identified from the gastric ulcer samples of sows with fatal gastrointestinal diseases.

(c) The Author(s). 2021 Open Access This article is licensed under a Creative Commons Attribution 4.0 International License, which permits use, sharing, adaptation, distribution and reproduction in any medium or format, as long as you give appropriate credit to the original author(s) and the source, provide a link to the Creative Commons licence, and indicate if changes were made. The images or other third party material in this article are included in the article's Creative Commons licence, unless indicated otherwise in a credit line to the material. If material is not included in the article's Creative Commons licence and your intended use is not permitted by statutory regulation or exceeds the permitted use, you will need to obtain permission directly from the copyright holder. To view a copy of this licence, visit http://creativecommons.org/licenses/by/4.0/ The Creative Commons Public Domain Dedication waiver (http://creativecommons.org/publicdomain/zero/1.0/) applies to the data made available in this article, unless otherwise stated in a credit line to the data. 


\section{Case presentation}

In late 2019, in a pig farm with a yearly scale of 5,000 sows and 10,000 fatting pigs located in Henan province, about $20 \%$ of pregnant and postpartum sows were suffering from a serious digestive tract disease with a mortality rate higher than $60 \%$. While no abnormalities in the piglets from the sick sows could be found after being transferred to the healthy sows. The sick sows had gastrointestinal symptoms such as blood in stool and vomiting. Necropsy revealed obvious gastric ulcers, gastrointestinal perforation, and intestinal hemorrhage in the gastrointestinal tract, but no lesions in other organs. An automatic feeding system was adopted on the farm, and the granular feed of the sows was switch to the type of flake in one week before the sows showed clinical symptoms. The flake feed was sent for the tests of zearalenone, ochratoxin A, vomitoxin, T-2 toxin, and aflatoxin B1, B2, G1, G2, (Luoyang Sino-science Gene, China) after the disease occurred, and all the test results were negative.

The damaged gastric mucosal tissues with ulcer of three dead sows were collected using sterile swabs from the sows dying from gastrointestinal diseases. The samples of gastric tissues were smeared on the clean glass slides. After fixation, the periodic acid-Schiff (PAS) staining kit (Solarbio, China) was used for morphological identification. The ovoid yeast-like cells that dark purple stained could be observed in gastric tissues of the three dead sows, with fungal spores and pseudohyphae (Fig. 1). In the histopathological assay, the gastric tissues were fixed in $10 \%$ formalin fixative solution for $24 \mathrm{~h}$, and then were placed in the embedded frame for dehydration and paraffin embedding. After slicing, staining, and mounting, the embedded samples were observed under the microscope. The results of H\&E staining showed gastric mucosal epithelium injury and abscess, with

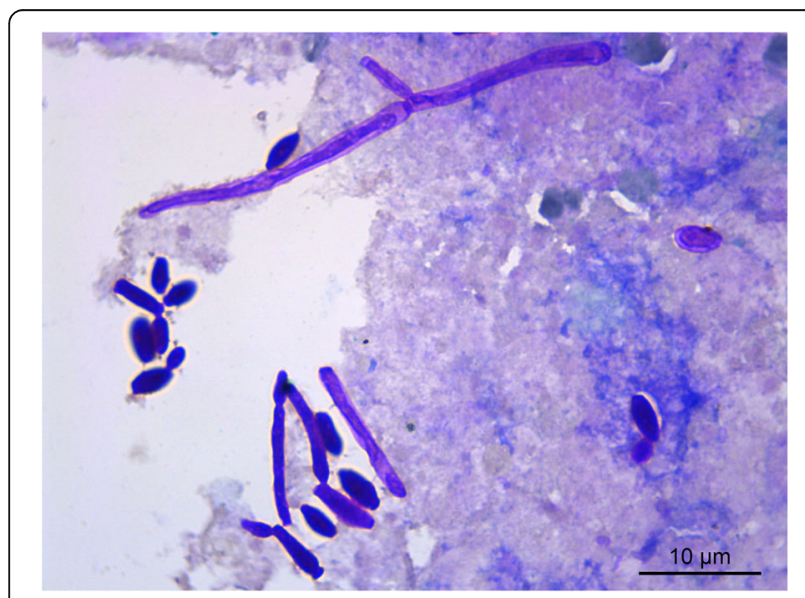

Fig. 1 Morphology of yeast-like cells after PAS staining of gastric tissue (1000x) yeast-like fungal spores and pseudohyphae in the exposed submucosa (Fig. 2).

For culture characteristics assay, the samples of gastric tissues were inoculated on Sabouraud dextrose agar (SDA) plate at $28{ }^{\circ} \mathrm{C}$, and Tryptic soy agar(TSA) plate containing $10 \%$ newborn bovine serum in $5 \% \mathrm{CO}_{2}$ at 37 ${ }^{\circ} \mathrm{C}$ for 3-5 days. After $48 \mathrm{~h}$ of incubation, a large number of monomorphic, cream-colored, smooth, glabrous colonies were observed on the SDA plate (Fig. 3), which consistent with the colony morphology of Candida, and no bacteria were grown on TSA plates. The Candidalike colonies on SDA plate were selected and streaked on SDA plate again for purification. After incubation at $28{ }^{\circ} \mathrm{C}$ for 3 days, one pure clone was picked for PAS staining and microscopy examination. After PAS staining, as observed in the smear microscopy, dark purple stained, ovoid yeast-like fungal spores and pseudohyphae of the pure colony could be found under microscopy (Fig. 4). The isolate was preliminarily identified as Candida.

The Candida isolate was further analyzed by PCR. DNA from the pure colony was extracted by fungi genomic DNA extraction kit (Solarbio, China) according to the manufacturer's instruction. The internal transcribed spacers (ITS) region of rDNA (ITS-rDNA) were amplified using fungal universal primers Its1 (5'-TCCGTAGG TGAACCTGCGG-3') and Its4 (5'-TCCTCCGCTT ATTGATATGC-3') [9]. The PCR cycle was as follows: $94{ }^{\circ} \mathrm{C}$ for $3 \mathrm{~min}$, followed by 30 cycles at $94^{\circ} \mathrm{C}$ for $30 \mathrm{sec}$, $53{ }^{\circ} \mathrm{C}$ for $30 \mathrm{sec}, 72^{\circ} \mathrm{C}$ for $1 \mathrm{~min}$. and with a final extension at $72{ }^{\circ} \mathrm{C}$ for $10 \mathrm{~min}$. The PCR products were analyzed by electrophoresis, an amplified fragment about 550 bp was obtained (Fig. 5).

To determine the species, the fragment about $550 \mathrm{bp}$ identified by ITS PCR was sent for sequencing (GENE WIZ, China). The sequencing results were analyzed by

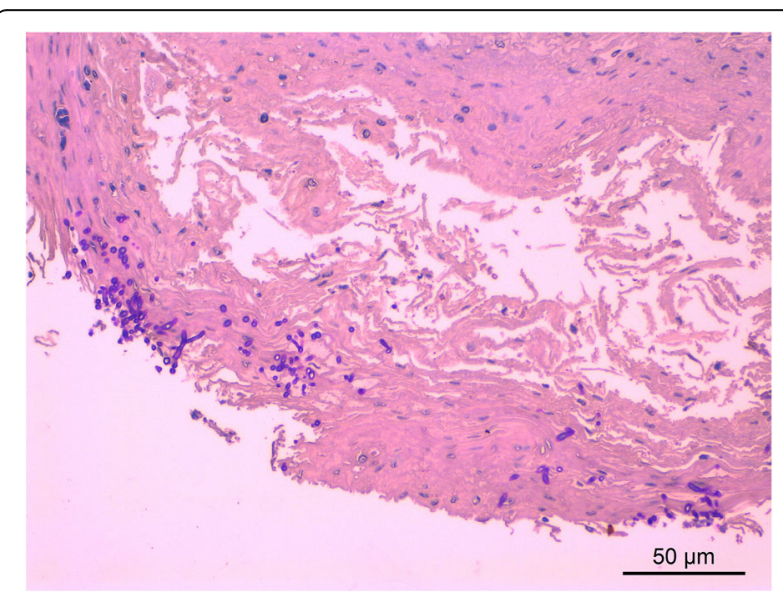

Fig. 2 Histopathological observation of the gastric sample $(H \& E, 200 x)$ 


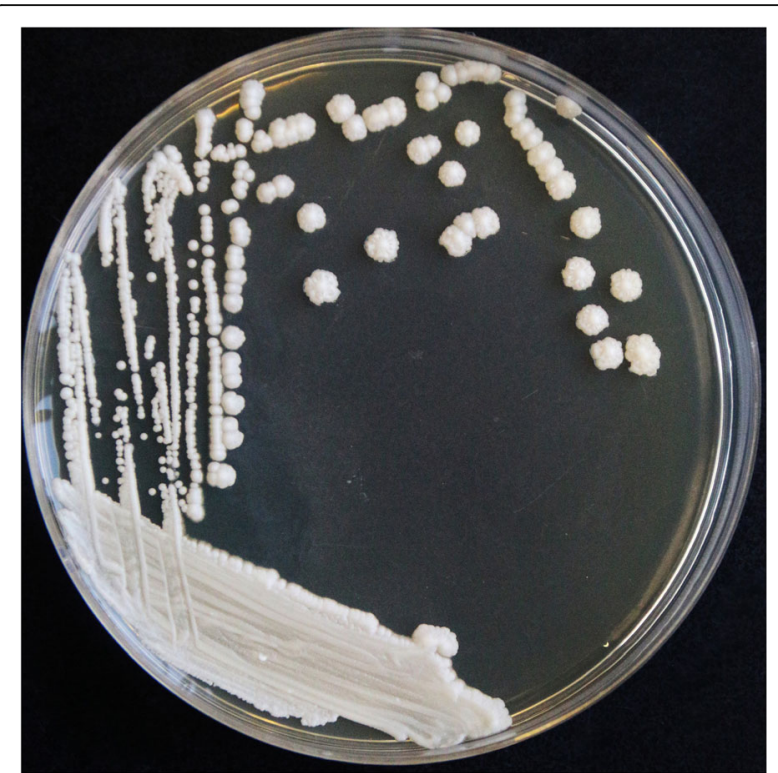

Fig. 3 Growth of yeast-like colonies on SDA plate (48 h post incubation)

BLAST on the National Center for Biotechnology Information (NCBI) database (). The sequence of ITS showed a nucleotide identity of $100 \%$ compared with that of the C. tropicalis in GenBank (GenBank accession No.CP047875.1), confirming that the isolate was C. tropicalis.

\section{Discussion and conclusions}

Usually, the causal factors for gastric ulcers in pigs including nutritional factors, physical aspects of feed [10], microbial infections, such as the bacteria of Helicobacter suis $[11,12]$. In this case of sows with gastric ulcers, we confirmed that no nutritional, toxic of the feed or bacteria factors involved.

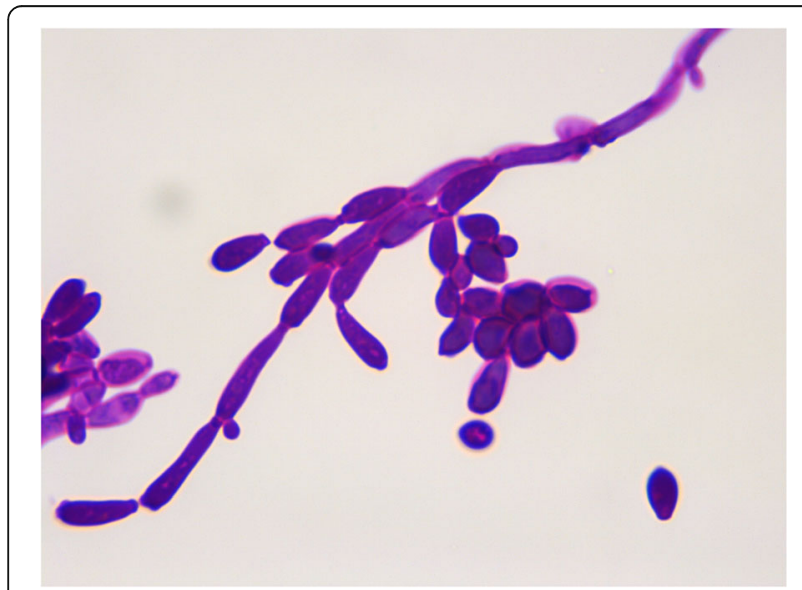

Fig. 4 Morphology of yeast-like cells after PSA staining of the pure colony $(1000 x)$

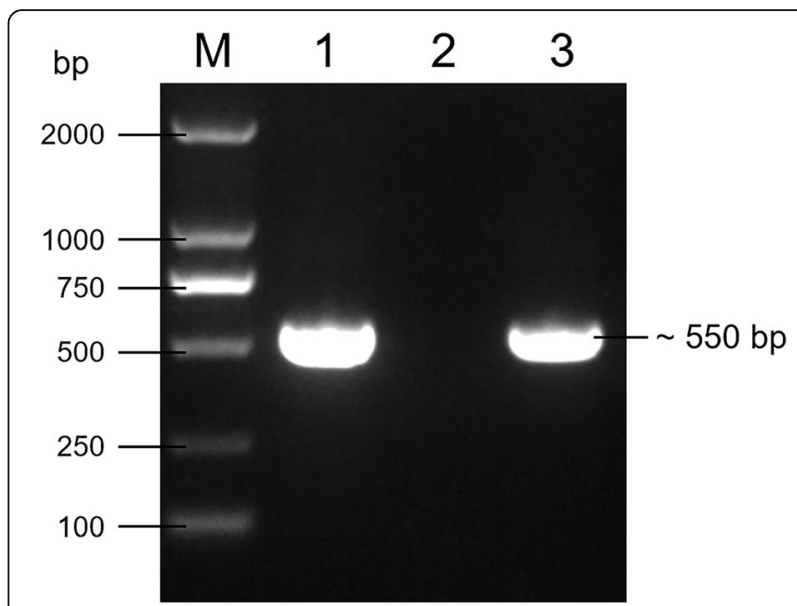

Fig. 5 The result of PCR amplification of ITS-rDNA region [M: DL2000 DNA Marker; 1: the isolated strain; 2: Negative control (nuclease-free water); 3: Fungus positive control (Candida Albicans strain ATCC 10,231)]

C. albicans is the main pathogen of human candidiasis. In recent years, the infection rate of non-Candida albicans, especially C. tropicalis, has increased [4, 13-17]. It has been reported that the candidiasis in swine is mainly caused by $C$. albicans. Here, for the first time, we reported the fatal infection of $C$. tropicalis in sows, and the Candida spp. was isolated from the gastric sample of infected animals.

Candida would rapidly proliferate at the damaged skin and mucosal surface, and then invade the body [4]. According to the investigation, the case in the pig farm may be related to feeding the sows with hard and flake feed after feed change, resulting the damage of mucosal ulcer in digestive tract, which promoted the infection of C. tropicalis by mucosal surface and caused fatal infection of the sows. Based on the laboratory diagnosis of $C$. tropicalis infection, the sows healthy in this pig farm was rapidly under controlled by strengthening the sanitation management, such as enclosing house, cleaning the feed trough, and feeding the digestible feed.

The traditional morphology and chromogenic mediumbased methods for Candida identification have no high requirements for experimental conditions, while are susceptible to the influence of culture conditions and passage. The molecular biology method based on the genotype difference of species in the nucleotide sequences with high accuracy. The ITS-rDNA region of fungi has extensive sequence polymorphism, which is highly conserved among different strains within a species, but significantly different among different species within a genus. The PCR and sequencing analysis of ITS-rDNA sequences in different Candida species, including C. albicans, C. parapsilosis, C. krusei, C. dubliniensis, C. guilliermondii and C. tropicalis, were consistent with the results of morphological and 
biochemical characterization [18]. This feature makes ITS suitable for molecular identification of fungal species [19]. So, in this study, after smear microscopy and histopathological assay of the diseased sows' samples, the case was preliminarily determined as Candida infection by the yeast-like fungi observation, and then further accurately and rapidly identified as $C$. tropicalis by ITS-rDNA PCR and sequencing.

\section{Acknowledgements}

Our greatest appreciation goes to Dr. Xiuling Yu and Dr. Xiaoying Wang of National Research Center for Veterinary Medicine for the guidance on the isolation and identification of fungi.

\section{Authors' contributions}

YX collected the clinical samples. LFZ, YXW, SGG, and YYJ were involved in the culture analysis with SDA. YZ, XFL and, ZS performed the PAS staining and histopathological assay. LFZ and QYZ performed the PCR and sequencing analyses. BCH drafted the manuscript. KGT and BCH critically read and edited the manuscript. All authors read and approved the final manuscript.

\section{Funding}

This study was supported by the Special Project of Industrial Cluster in Selfcreated Zone in Zhengzhou, Luoyang, and Xinxiang Cities (181200211700) for clinical sample collection, testing, sequencing, and data analysis of the nucleic acid sequence.

\section{Availability of data and materials}

All data generated or analyzed during this study are included in this published article.

\section{Ethics approval and consent to participate}

This study did not require the approval of an ethical committee since it is a case report.

\section{Consent for publication}

Not applicable.

\section{Competing interests}

The authors declare that they have no competing interests.

Received: 21 September 2020 Accepted: 25 February 2021

Published online: 05 March 2021

\section{References}

1. Jarvis WR. Epidemiology of nosocomial fungal infections, with emphasis on Candida species. Clin Infect Dis. 1995;20(6):1526-30.

2. Deak R, Bodai L, Aarts HJ, Maraz A. Development of a novel, simple and rapid molecular identification system for clinical Candida species. Med Mycol. 2004:42(4):311-8.

3. Jung SI, Shin JH, Song JH, Peck KR, Lee K, Kim MN, Chang HH, Moon CS. Korean Study Group for C: Multicenter surveillance of species distribution and antifungal susceptibilities of Candida bloodstream isolates in South Korea. Med Mycol. 2010;48(4):669-74.

4. Kothavade RJ, Kura MM, Valand AG, Panthaki MH. Candida tropicalis: its prevalence, pathogenicity and increasing resistance to fluconazole. J Med Microbiol. 2010;59(Pt 8):873-80.

5. Subramanya SH, Sharan NK, Baral BP, Hamal D, Nayak N, Prakash PY, Sathian B, Bairy I, Gokhale S. Diversity, in-vitro virulence traits and antifungal susceptibility pattern of gastrointestinal yeast flora of healthy poultry, Gallus gallus domesticus. BMC Microbiol. 2017;17(1):113.

6. Cordeiro Rde A, de Oliveira JS, Castelo-Branco Dde S, Teixeira CE, Marques FJ, Bittencourt PV, Carvalho VL, Bandeira Tde J, Brilhante RS, Moreira JL, et al. Candida tropicalis isolates obtained from veterinary sources show resistance to azoles and produce virulence factors. Med Mycol. 2015;53(2):145-52.

7. Ozawa H, Okabayashi K, Kano R, Watari T, Watanabe S, Hasegawa A. Rapid identification of Candida tropicalis from canine cystitis. Mycopathologia. 2005;160(2):159-62.
8. Ebani W, Nardoni S, Bertelloni F, Najar B, Pistelli L, Mancianti F. Antibacterial and Antifungal Activity of Essential Oils against Pathogens Responsible for Otitis Externa in Dogs and Cats. Medicines (Basel) 2017, 4(2).

9. Chen YC, Eisner JD, Kattar MM, Rassoulian-Barrett SL, Lafe K, Bui U, Limaye AP, Cookson BT. Polymorphic internal transcribed spacer region 1 DNA sequences identify medically important yeasts. J Clin Microbiol. 2001;39(11): 4042-51.

10. Ayles HL, Friendship RM, Ball RO. Effect of dietary particle size on gastric ulcers, assessed by endoscopic examination, and relationship between ulcer severity and growth performance of individually fed pigs. Swine Health Production. 1996:4(5):211-6.

11. Hellemans A, Chiers K, Decostere A, De Bock M, Haesebrouck F, Ducatelle R. Experimental infection of pigs with 'Candidatus Helicobacter suis'. Vet Res Commun. 2007;31(4):385-95.

12. De Bruyne E, Flahou B, Chiers K, Meyns T, Kumar S, Vermoote M, Pasmans F, Millet S, Dewulf J, Haesebrouck F, et al. An experimental Helicobacter suis infection causes gastritis and reduced daily weight gain in pigs. Vet Microbiol. 2012;160(3-4):449-54.

13. Nguyen MH, Peacock JE Jr, Morris AJ, Tanner DC, Nguyen ML, Snydman DR, Wagener MM, Rinaldi MG, Yu VL. The changing face of candidemia: emergence of non-Candida albicans species and antifungal resistance. Am J Med. 1996:100(6):617-23.

14. Abi-Said D, Anaissie E, Uzun O, Raad I, Pinzcowski H, Vartivarian S. The epidemiology of hematogenous candidiasis caused by different Candida species. Clin Infect Dis. 1997;24(6):1122-8.

15. Pfaller MA. Nosocomial candidiasis: emerging species, reservoirs, and modes of transmission. Clin Infect Dis. 1996;22(Suppl 2):89-94.

16. Silva S, Negri M, Henriques M, Oliveira R, Williams DW, Azeredo J. Candida glabrata, Candida parapsilosis and Candida tropicalis: biology, epidemiology, pathogenicity and antifungal resistance. FEMS Microbiol Rev. 2012;36(2): 288-305.

17. Wang $H, X u Y C$, Hsueh PR. Epidemiology of candidemia and antifungal susceptibility in invasive Candida species in the Asia-Pacific region. Future Microbiol. 2016;11:1461-77

18. Boyanton BL Jr, Luna RA, Fasciano LR, Menne KG, Versalovic J. DNA pyrosequencing-based identification of pathogenic Candida species by using the internal transcribed spacer 2 region. Arch Pathol Lab Med. 2008; 132(4):667-74.

19. Turroni F, Foroni E, Pizzetti P, Giubellini V, Ribbera A, Merusi P, Cagnasso P, Bizzarri B, de'Angelis GL, Shanahan F, et al. Exploring the diversity of the bifidobacterial population in the human intestinal tract. Appl Environ Microbiol. 2009:75(6):1534-45.

\section{Publisher's Note}

Springer Nature remains neutral with regard to jurisdictional claims in published maps and institutional affiliations.

Ready to submit your research? Choose BMC and benefit from

- fast, convenient online submission

- thorough peer review by experienced researchers in your field

- rapid publication on acceptance

- support for research data, including large and complex data types

- gold Open Access which fosters wider collaboration and increased citations

- maximum visibility for your research: over $100 \mathrm{M}$ website views per year

At BMC, research is always in progress.

Learn more biomedcentral.com/submissions 